\title{
BMJ Open Healthcare to parents of young terrorism survivors: a registry-based study in Norway
}

\author{
Jon Magnus Haga, ${ }^{1,2}$ Siri Thoresen, ${ }^{1}$ Lise Eilin Stene, ${ }^{1}$ Tore Wentzel-Larsen, ${ }^{1,3}$ \\ Grete Dyb $b^{1,2}$
}

To cite: Haga JM, Thoresen S, Stene LE, et al. Healthcare to parents of young terrorism survivors: a registry-based study in Norway. BMJ Open 2017;7:e018358. doi:10.1136/ bmjopen-2017-018358

- Prepublication history and additional material for this paper are available online. To view these files, please visit the journal online (http://dx.doi. org/10.1136/bmjopen-2017018358).

Received 23 June 2017 Revised 19 September 2017 Accepted 3 October 2017

\section{Check for updates}

${ }^{1}$ Norwegian Centre of Violence and Traumatic Stress Studies (NKVTS), Oslo, Norway

${ }^{2}$ Faculty of Medicine, Institute of Clinical Medicine, University of Oslo, Oslo, Norway

${ }^{3}$ Centre for Child and Adolescent Mental Health, Eastern and Southern Norway, Oslo, Norway

Correspondence to

Dr Jon Magnus Haga;

j.m.haga@medisin.uio.no

\section{ABSTRACT}

Objectives To assess changes in parents' short-term and long-term primary and specialised healthcare consumption following a terrorist attack threatening the lives of their children.

Design Registry-based study comparing parental healthcare service consumption in the 3 years before and the 3 years after a terrorist attack.

Setting The aftermath of the Utøya terrorist attack. The regular, publicly funded, universal healthcare system in Norway. Parents learning of a terrorist attack on their adolescent and young adult child ren. Participants Mothers $(n=226)$ and fathers $(n=141)$ of a total of 263 survivors of the Utøya terrorist attack (54.6\% of all survivors $13-33$ years, $\mathrm{n}=482$ ).

Main outcome measures We report primary and specialised somatic and mental healthcare service consumption in the early (0-6 months) and delayed (>6-36 months) aftermath of the attack, both in terms of frequency of services consumed (assessed by ageadjusted negative binomial hurdle regression) and proportions of mothers and fathers provided for (mean semiannual values). The predisaster and postdisaster rates were compared by rate ratios (RRs), and $95 \% \mathrm{Cl}$ were generated through bootstrap replications.

Results Frequency of primary healthcare service consumption increased significantly in both mothers and fathers in the early aftermath of the attack (mothers: $\mathrm{RR}=1.97,95 \% \mathrm{Cl} 1.76$ to 2.23 ; fathers: $\mathrm{RR}=1.73,95 \% \mathrm{Cl} 1.36$ to 2.29 ) and remained significantly elevated throughout the delayed aftermath. In the specialised mental healthcare services, a significant increase in the frequency of service consumption was observed in mothers only (early: $\mathrm{RR}=7.00,95 \% \mathrm{Cl}$ 3.86 to 19.02 ; delayed: $\mathrm{RR}=3.20,95 \% \mathrm{Cl}$ 1.49 to 9.49 ). In specialised somatic healthcare, no significant change was found.

Conclusion Following terrorist attacks, healthcare providers must prepare for increased healthcare needs in survivors and their close family members, such as parents. Needs may present shortly after the attack and require long-term follow-up.

\section{Strengths and limitations of this study}

- This study employs an objective measure on healthcare consumption before and after a terrorist attack.

- The context of the study is a public, accessible and well-developed healthcare system.

- High number of both mothers and fathers participated. However, the full size of the parent population remains unknown.

- Only services provided by healthcare professionals were included. Psychosocial support from other professionals was not included.

\section{INTRODUCTION}

Life threat to a child may jeopardise parents' long-term health. Diagnostic and Statistical Manual of Mental Disorders fifth edition ${ }^{1}$ recognises learning that a close family member is being threatened with death or serious injury as being a potentially traumatising event. In recent years, numerous terrorist attacks have targeted children, adolescents and young adults who are not with their parents, either at school or during their leisure time (eg, summer camp, night club, café, concert hall ${ }^{2-7}$ ). Despite widespread concern about the postdisaster health of terrorism survivors, their parents' postdisaster reactions, coping and needs have received little attention.

Adverse health effects from experiencing life threat to one's child have previously been addressed in parents of seriously ill children. Elevated levels of parental anxiety, depression and post-traumatic stress reactions have been reported both following acute ${ }^{89}$ and chronic disease, ${ }^{10} 11$ as well as in the wake of traffic accidents $^{12}{ }^{13}$. Likewise, in parents of sexually abused children ${ }^{14}$ and in parents of young soldiers deployed to hostile environments, ${ }^{16} 17$ substantial emotional distress have been shown to persist for years. Several population-based studies have addressed the 
emotional impact of terrorism on individuals physically distant from the site of a terrorist attack. ${ }^{18-23}$ However, only one study has specifically addressed distress in parents who witnessed or learnt of a terrorist attack that threatened the lives of their own children. ${ }^{2}$ This small study $(n=20$ mothers) reported parental distress at levels comparable to those of the young survivors themselves. Traumatisation has previously also been shown to be associated with somatic health complaints, including respiratory, gastrointestinal and cardiovascular disease. ${ }^{24-26}$ A registry-based study of parents who learnt that their adolescent and young adult children were caught in a pub fire in the Netherlands in 2001 reported that the postdisaster incidence of cardiovascular health problems, as recorded by the primary healthcare provider, was significantly higher in parents of burnt survivors than in unaffected community controls. ${ }^{27}$ Thus, although limited, current evidence suggests that terrorism may potentially elicit both mental and somatic healthcare needs in parents of survivors.

Our previous studies of the mothers and fathers of the Utøya survivors have demonstrated substantial and lasting levels of emotional distress. ${ }^{28}{ }^{29}$ The present study employs national registry-based healthcare data to assess the parents' primary and specialised healthcare consumption before and after the terrorist attack. Separately in mothers and fathers, we first investigated whether the frequency of parents' primary and specialised healthcare service consumption in the early (0-6 months) and delayed (>6-36 months) aftermath of the terrorist attack was higher than in the 3-year period before the terrorist attack. Second, we examined whether the semiannual proportions of mothers and fathers consuming one or more healthcare services were increased (early and delayed), when compared to predisaster levels. Third, we assessed the reasons for parents accessing healthcare services in the aftermath of the terrorist attack, by mapping out reasons for encountering the primary healthcare services, the entry point to the healthcare system in Norway.

\section{METHOD}

\section{Setting}

The setting of this study is the aftermath of the Utøya terrorist attack.

\section{Trauma}

On 22 July 2011, two terrorist attacks shook Norway. A single perpetrator detonated a bomb in the government quarter in Oslo, before setting out on a shooting spree at the youth summer camp on Utøya Island less than 2 hours later. The youth were trapped on the small island with the perpetrator for more than 1 hour. The attack left 69 dead and 495 alive, of whom 35 had sustained severe physical injuries. ${ }^{30}$ The parents, all physically distant from the island, watched events unfold via live media reports. Some parents had access to intermittent telecommunication with their offspring on the island. Following the attack, the survivors were reunited with their families throughout the country.

\section{Post-trauma care}

Soon after the terrorist attack, an early proactive outreach programme was established, in line with the current trauma-informed consensus of expert opinions. ${ }^{31}$ Multi-disciplinary crisis teams, established in affected municipalities $(\mathrm{n}=128)$, were to provide the immediate psychosocial support to those in need; dedicated contact persons were to proactively monitor and support the affected families throughout the first year postdisaster and to facilitate access to regular healthcare services as required. ${ }^{28}{ }^{32}$ Postdisaster healthcare services were provided by the regular two-level healthcare system in Norway: ${ }^{33}$ level 1 , including the primary healthcare services of general practitioners (GPs) and emergency primary healthcare, provides services for both somatic and mental health complaints and acts as the entry point and gatekeeper to secondary healthcare services; level 2, the secondary healthcare services, provides specialised mental and specialised somatic healthcare services and is accessed through medical referrals only. Regular healthcare services in Norway are publicly funded and accessible throughout the country.

\section{Design}

This is a longitudinal, prospective study, assessing registry-based data on parental healthcare consumption in the periods 3 years before and after the terrorist attack (22 July 2008 to 21 July 2014).

\section{Procedure}

Parental recruitment and participation in the earlier waves of the larger Utøya study have been explained in detail previously. ${ }^{28}{ }^{34}$ In summary, the earlier waves had open cohort designs, extending invitations to all eligible participants (parents of survivors 13-33 years, $\mathrm{n}=482$ ). The third wave of the study, on which this paper reports, had a closed cohort design, meaning that only parents who had participated in either of the previous waves $(n=532)$ were invited. Invitations to the third wave were distributed by mail at three years after the disaster and included information on how to opt out.

\section{Sample}

Overall, 299 mothers and 233 fathers ( $\mathrm{n}=532$ parents) participated in at least one of the three waves of the Utøya study; $75.5 \%$ of the mothers $(n=226)$ and $60.5 \%$ of the fathers $(n=141)$ took part in wave 3 . The participants represented 251 distinct families and cared for a total of 263 survivors $(54.6 \%$ of all Utøya survivors aged 13-33 years). Mean ages of mothers and fathers at the time of the attack were 46.7 (SD 5.8) and 49.7 (SD 5.9) years, respectively. A majority of the parents were of Norwegian origin ( $n=335,92.0 \%$, missing $n=3)$, held a university or a university college degree $(n=225$, $61.3 \%)$, had an average or above-average financial 
situation $(n=297,80.9 \%)$ and were, at the time of data collection, mostly employed $(n=314,86.3 \%$, missing $\mathrm{n}=3)$. Attrition from previous waves $(\mathrm{n}=165,31.0 \%)$ favoured male gender (OR 2.02, $\left.\chi^{2} \mathrm{p}<0.001\right)$. Neither non-Norwegian origin (OR: mothers $=1.00, \chi^{2} \mathrm{p}=0.996$; fathers $=1.15, \chi^{2} \mathrm{p}=0.805$ ) nor levels of early post-traumatic stress reactions (mean-mothers: 1.34 vs 1.34 , Student's t-test $p=0.967$; fathers: 0.80 vs 0.88 , Student's t-test $\mathrm{p}=0.358$ ) were associated with non-participation at wave 3. Most participants consented to collection of registry-based data (mothers: $\mathrm{n}=222,98.5 \%$; fathers: $\mathrm{n}=136,96.5 \%)$.

\section{Measures}

Primary healthcare consumption was assessed through the Health Economics Administration (HELFO) database by analysing reimbursement claims filed by primary healthcare providers, GPs, to the national insurance scheme. All records dating from 22 July 2008 to 21 July 2014 were included, regardless of whether they referred to services provided at a GP clinic, during house calls, by telephone or mail, provided by regular GPs or locum GPs, within regular office hours or when on-call. A total of 13419 records were identified, of which $42(0.3 \%)$ were duplicates (matching date, time, diagnosis, provider and mode of contact). The non-duplicates $(\mathrm{n}=13377)$ were subdivided according to the type and time of service (online supplementary table 1). Reason for encountering was recorded according to International Classification of Primary Care revised 2nd edition (ICPC-2) ${ }^{35}$ and clustered according to type of health problem. ${ }^{36}$

Specialised healthcare consumption was assessed using the Norwegian Patient Registry (NPR)—activity reported by hospitals and hospital clinics-and the HELFO database-reimbursement claims filed to the National Insurance Scheme by private specialised healthcare providers. All services recorded by physicians and psychologists dating from 22 July 2008 to 21 July 2014 were included, irrespective of whether the service was provided in a public hospital, a private clinic, by telephone or mail and within regular office hours or not. A total of 6024 specialised healthcare services were identified (NPR $n=4152$ services, HELFO database $n=1872$ ), of which 193 (3.2\%) were duplicates (matching date, diagnosis, healthcare provider and mode of contact). The services were subdivided into specialised mental healthcare services $(n=2079)$ and specialised somatic healthcare services $(n=3752)$ and, further, according to type and time of service (online supplementary table 1).

Quality of data: Claims to the national insurance scheme (HELFO) are submitted electronically. All claims with missing patient IDs are automatically rejected and returned to the healthcare provider for resubmission. Thus, the HELFO database contains no data with missing patient ID. In contrast, NPR does not reject incomplete information and consequently contains a small number of entries with missing patient ID (online supplementary table 2).

\section{Statistics}

The data analysed in this paper are count data (ie, frequencies of occurrences within a predefined time period) that were recorded in the 3 years before and after a terrorist attack. Mothers and fathers were assessed separately throughout the paper.

Descriptive statistics are presented graphically. The distribution of overall frequencies by which healthcare services were accessed before and after the terrorist attack is presented as split violin diagrams. ${ }^{37}$ Rates of healthcare service consumption across the study period and the proportions of individuals accessing healthcare services semiannually are presented by line and pie charts, in a second figure. As is often found in data on healthcare consumption, ${ }^{38}$ our data were overdispersed (variance greater than the mean value) and exhibited excess zeros (individuals with no occurrences). Numerical values mirroring the graphics included in the paper are tabulated in the online supplementary material.

The statistical analyses included in this paper compare postdisaster with predisaster healthcare consumption. Parents' age was hypothesised to influence healthcare needs independently of the terrorist attack being investigated. Thus, rates of partents' predisaster and postdisaster healthcare consumption were predicted from age-adjusted regression models, rather than assessing the observed predisaster and postdisaster values directly. Negative binomial hurdle regressions were chosen for rate predictions, as this method is well suited for overdispersed count data exhibiting excess zeros. ${ }^{39}$ In order for results to be interpreted in terms of rates, negative binomial hurdle regressions need to be offset for the observational period, also known as the person-time at risk. In our material, hospital admissions were considered to make an individual unavailable for healthcare services by other healthcare providers. Thus, in our study, observational periods were defined as days of non-hospitalisation within each time period being investigated. Negative binominal hurdle regression is a two-component regression model. ${ }^{39}$ Thus, model predictions need to be calculated for a predefined index individual. In our study, the index parent was defined as a mother or a father of 47 years of age at the time of the attack, reflecting the median age of the full parent sample. We chose to make predictions for the same age in both mothers and fathers, despite the father sample being slightly older than the mother sample, in order to increase comparability.

The detailed statistical procedure was as follows. First, predictions of frequency of healthcare service consumption were made for each period of interest, that is, predisaster and the early and delayed aftermath. Second, annualised rates of healthcare service consumption were obtained by dividing predicted frequencies by the duration of the time period investigated (ie, before $=36$ months, early aftermath $=6$ months, delayed aftermath $=30$ months). Additionally, the proportion of mothers and fathers acquiring 
services within a 6-month period was calculated by averaging observed semiannual proportions (by design, the frequency of non-zero predictions equals the observed value in negative binomial hurdle regressions). Finally, postdisaster versus predisaster rate ratios (RRs) were computed by dividing the rates of early and delayed postdisaster healthcare consumption (both the frequency of service consumption and the proportion of individuals accessing services) by the corresponding predisaster rates. Bias-corrected and accelerated $95 \%$ CI of RR were generated through bootstraps of 10000 replications.

All analyses were made using the full dataset, which included all services provided by primary and specialised healthcare service providers. As supplementary material, the analyses were repeated on a dataset including only in person consultations with the healthcare provider (ie, excluding the telephone consultations, mail correspondence, etc).

Across the time period investigated, improved quality of reporting practices to NPR was observed (fewer entries were recorded with missing patient IDs, online supplementary table 2). The improved quality of reporting practices was most evident between 2009 and 2010. In the final year predisaster, levels of missing patient IDs were not substantially different to postdisaster levels. As incomplete entries in NPR may have resulted in an underestimation of pre-disaster healthcare consumption, sensitivity analyses were performed by repeating all analyses that included the 3-year predisaster NPR data, with NPR data from the final year predisaster only.

Analyses were performed with R V.3.0.3 (R Foundation for Statistical Computing), with the R-packages pscl (1.4.9) for hurdle regressions and boot (1.3-13) for bootstrap analyses. Violin plots were generated through an adaptation of the vioplot (0.2) package.

\section{RESULTS}

The overall aim of this study was to create a detailed description of predisaster and postdisaster patterns of parental healthcare consumption. Thus, we began by mapping out the frequency distributions by which each parent accessed healthcare services in the periods 3 years before and after the attack (figure 1A,B). Notably, in primary healthcare, nearly all parents were found to have accessed healthcare services on one or more occasion both predisaster and postdisaster. In the specialised mental healthcare services, only a minority of the parents had received services. High variability in frequency of acquisition was found for both services.

Figure 2A,B descriptively outlines the trajectories of healthcare consumption over time. Upper halves of figures (line charts) report the annual rates at which healthcare services were provided to the parents before and after the attack. Bottom halves of figures (pie charts) report the numbers and proportion of parents provided for within each 6-month period. Notably, in the early aftermath of the attack, we observed a sharp increase in frequency of both primary and specialised mental healthcare services acquired. In the delayed aftermath, the observed frequency of healthcare service acquisition largely levelled out.

Figure $3 \mathrm{~A}, \mathrm{~B}$ presents the output of the statistical analyses comparing predisaster and postdisaster healthcare consumption. The horizontal axes indicate the RR of postdisaster versus predisaster healthcare consumption. The dotted vertical line indicates no difference $(R R=1)$. A statistically significant difference is indicated when the 95\% CI does not overlap this line. First, rates of healthcare services used (figure 3A) before and after the attack were addressed. We found that age-adjusted predictions of primary healthcare service consumption rates in mothers and fathers were significantly elevated both in the early and delayed aftermath, when compared with the 3-year period before the terrorist attack. Similarly, in mothers, but not in fathers, a significant increase in rates of postdisaster specialised mental healthcare service consumption was demonstrated, both in the early and delayed aftermath. In fathers, specialised mental healthcare service consumption could not be reliably bootstrapped, due to an insufficient number of occurrences. No significant increase in rates was found in the specialised somatic healthcare services. Second, we compared the proportion of individuals using the services (figure 3B) before and after the attack. We found that, compared with predisaster values, significantly more mothers and fathers used primary healthcare services, both in the early and delayed aftermath. Furthermore, significantly more mothers and fathers used specialised mental healthcare services in the early aftermath, when compared with predisaster levels. In the delayed aftermath, the numbers of mothers, but not fathers, using the specialised mental healthcare services remained significantly elevated. Sensitivity analyses addressing the improved reporting practices to NPR across the study period consistently returned conclusions that were not appreciably different to the findings presented in this paper and are not shown.

Finally, we assessed the reasons for parents encountering the healthcare services in the aftermath of the attack, as recorded by the primary healthcare providers at the time of the services' provision (figure 4). Notably, psychological health complaints dominated reasons for encountering in both genders. In fact, $78.4 \%$ of mothers $(n=174)$ and $47.1 \%$ of fathers $(n=64)$ consulted their GP about psychological complaints (ICPC-2, chapter 'P') in the aftermath of the attack. More than one-third were diagnosed with depression (mothers: $\mathrm{n}=42,19.0 \%$; fathers: $\mathrm{n}=15,11.0 \%$ ) or post-traumatic stress disorder (PTSD) (mothers: $\mathrm{n}=14$, $6.3 \%$; fathers: $\mathrm{n}=10,7.4 \%$ ) or both (mothers: $\mathrm{n}=9$, $4.1 \%$; fathers: $\mathrm{n}=4,2.9 \%$ ). Individuals with psychological health complaints were largely managed by primary healthcare services without receiving specialised mental healthcare services (mothers: $\mathrm{n}=106$, $60.9 \%$; fathers: $n=47,73.4 \%$ ). 


\section{A mothers $(n=222)$}

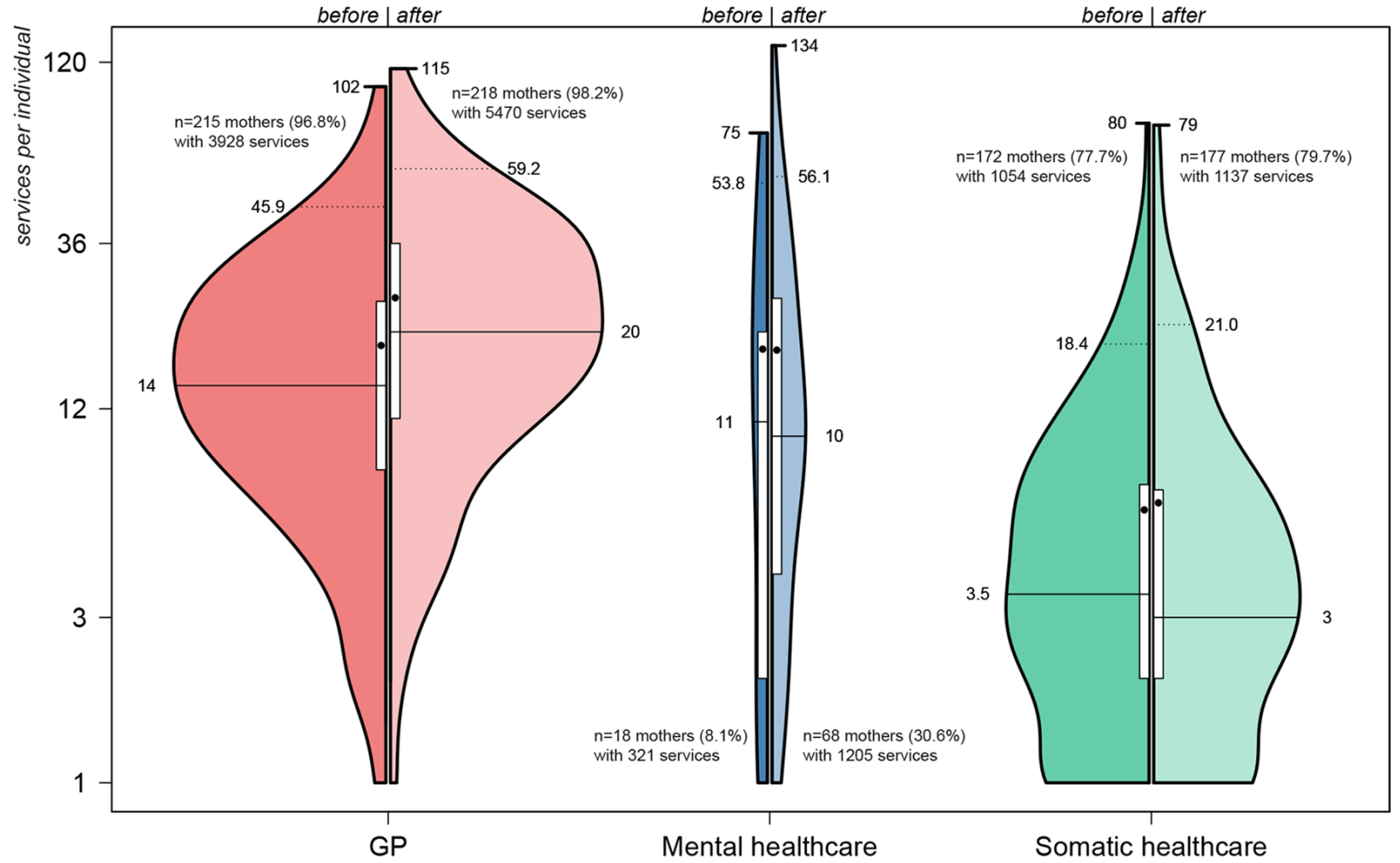

\section{$B$ fathers $(n=136)$}

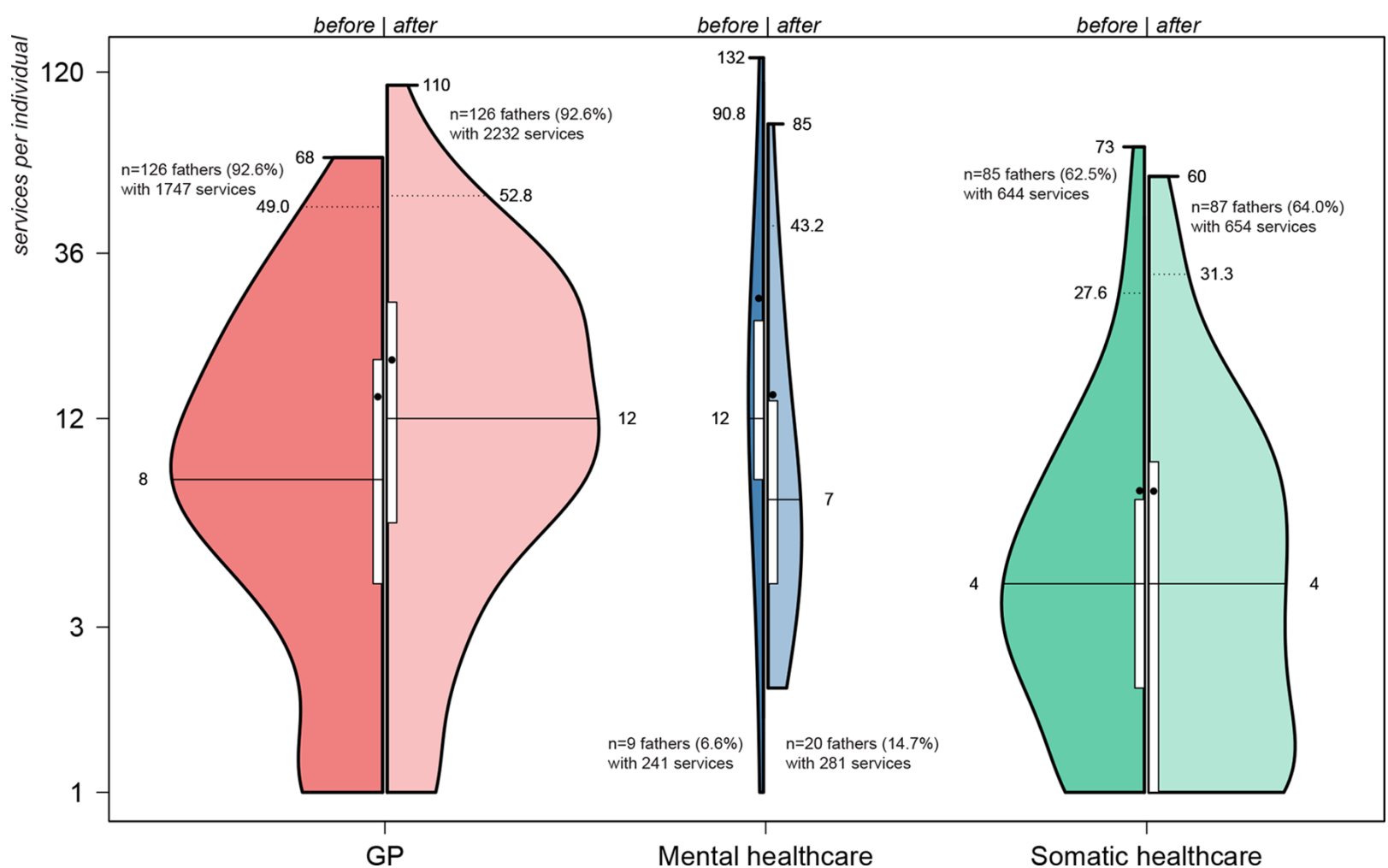

Figure 1 (A and B) Split-violin diagrams presenting frequency distributions of parents' overall healthcare service consumption before (left violins) and after (right violins) the terrorist attack. The vertical axes indicate the frequency by which the healthcare services were used. Each curve represents a Kernel density estimation, in which the area under curves reflect the proportion of mothers and fathers accessing the services. White vertical box: interquartile range (Q1-Q3). Black bullet: mean value. Solid horizontal line: median value. Dotted horizontal line: 95th percentile. Upper edge: maximum value. 


\section{A mothers $(\mathbf{n}=222)$}

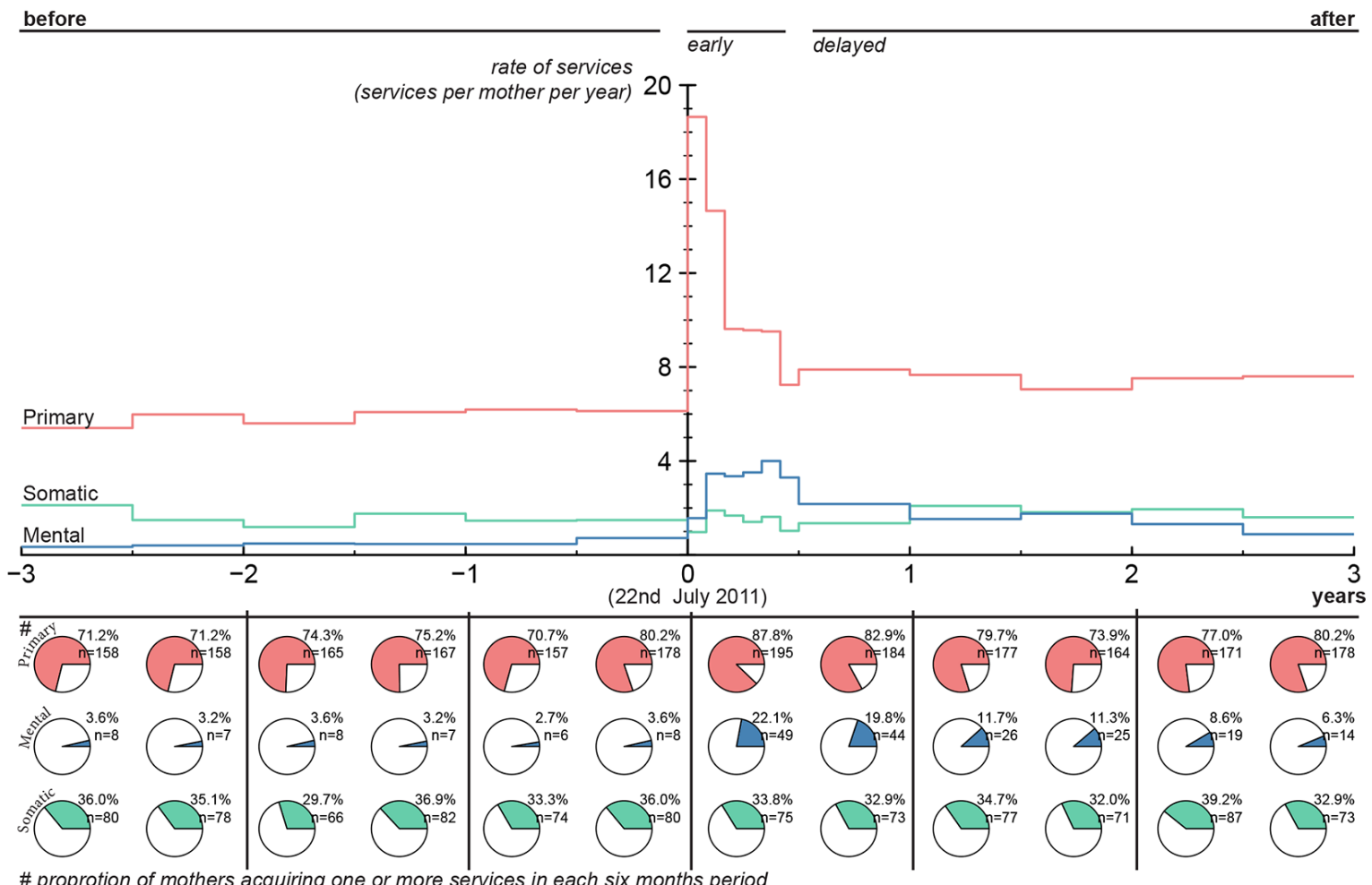

\section{B fathers $(n=136)$}

before

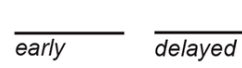

after

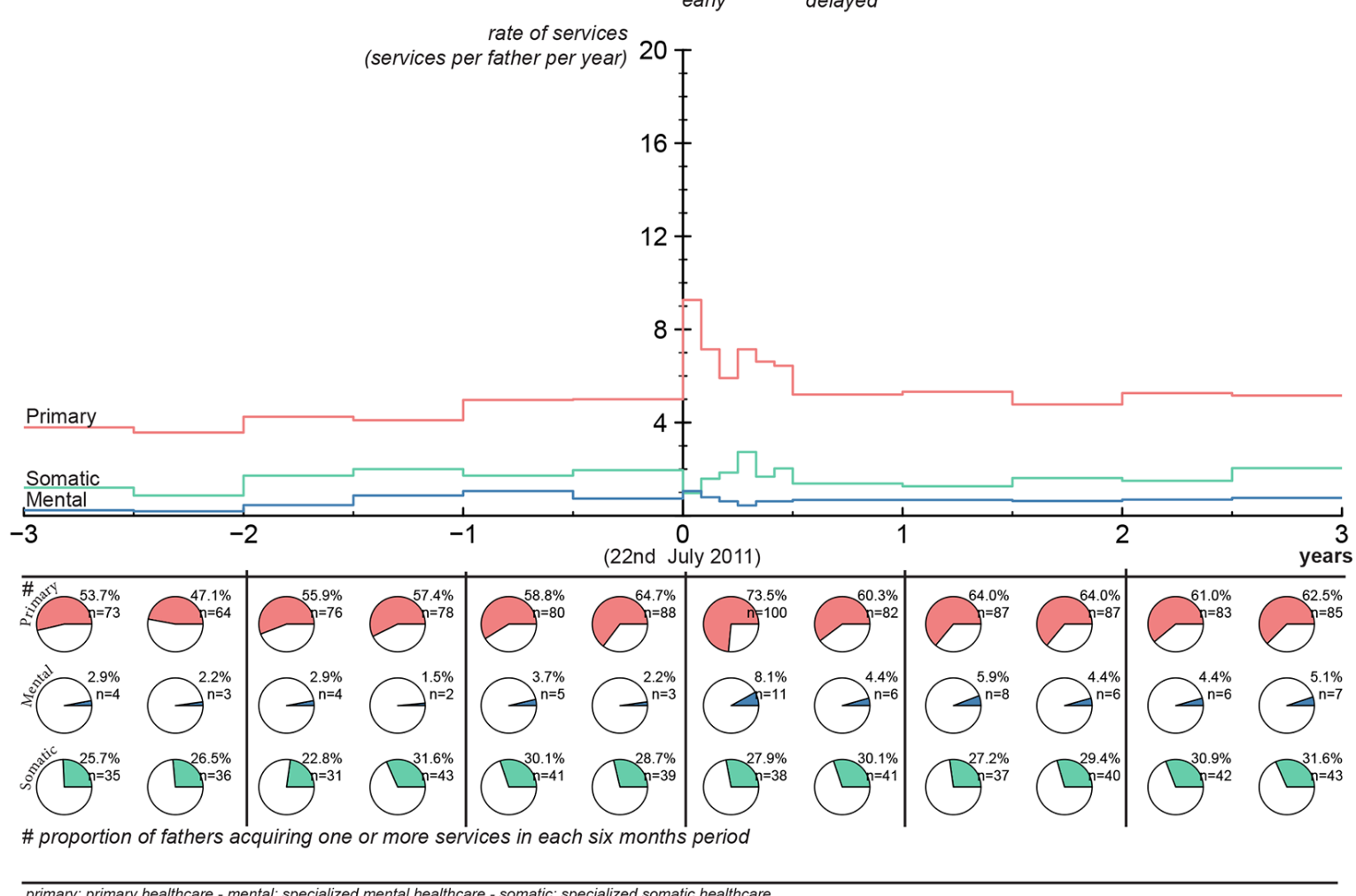

Figure 2 ( $\mathrm{A}$ and B) Healthcare service consumption across time, presented as rates of services used (line chart) and proportions of mothers and fathers provided for within each 6-month period (pie chart). Corresponding numeric values and values for in person consultations only are available in online supplementary table 3. 
A services

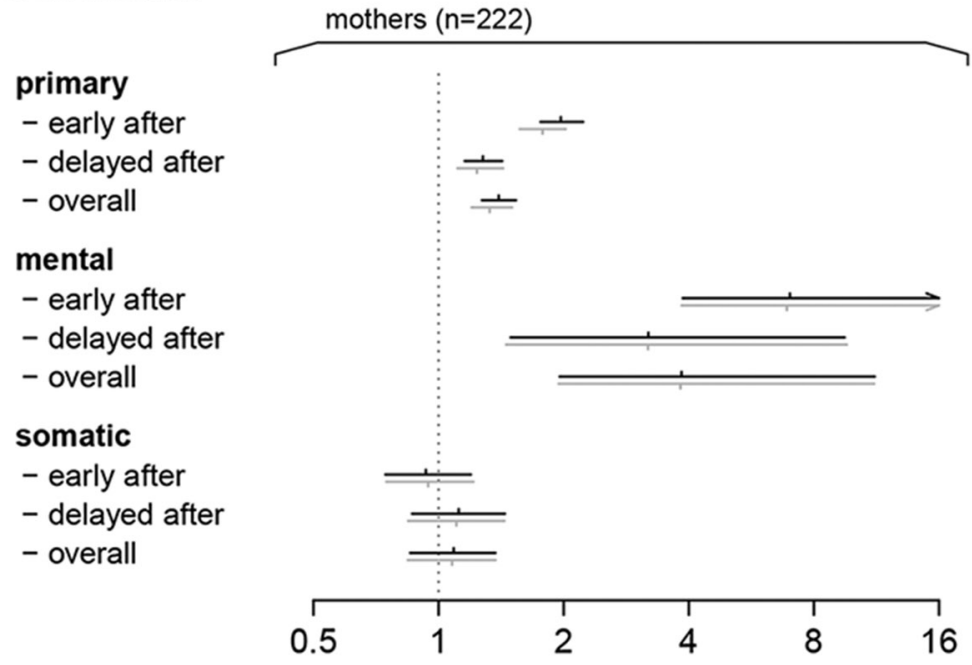

\section{$B$ individuals}
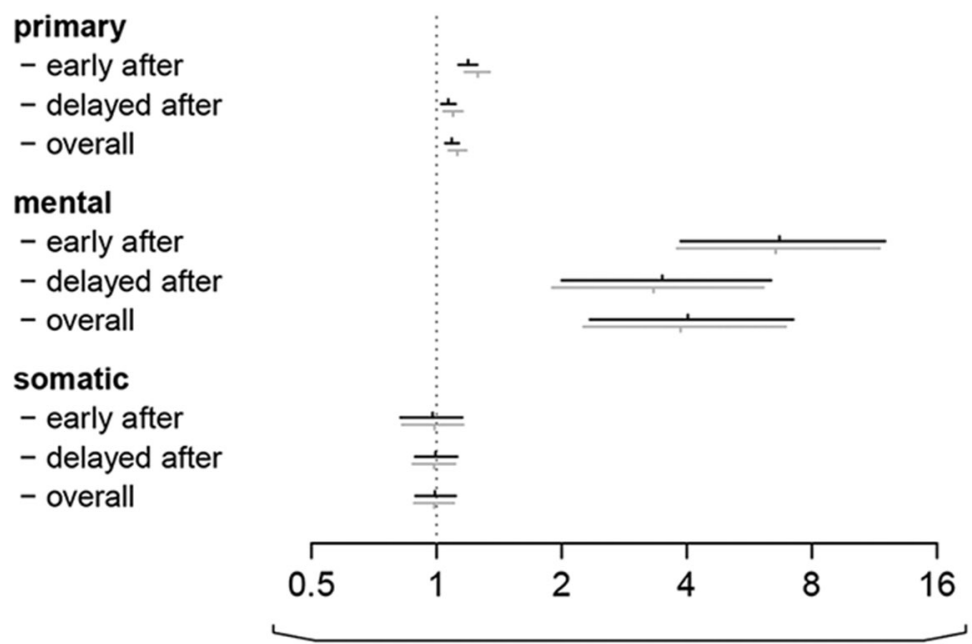

ALL HEALTHCARE SERVICES

CONSULTATIONS ONLY (-

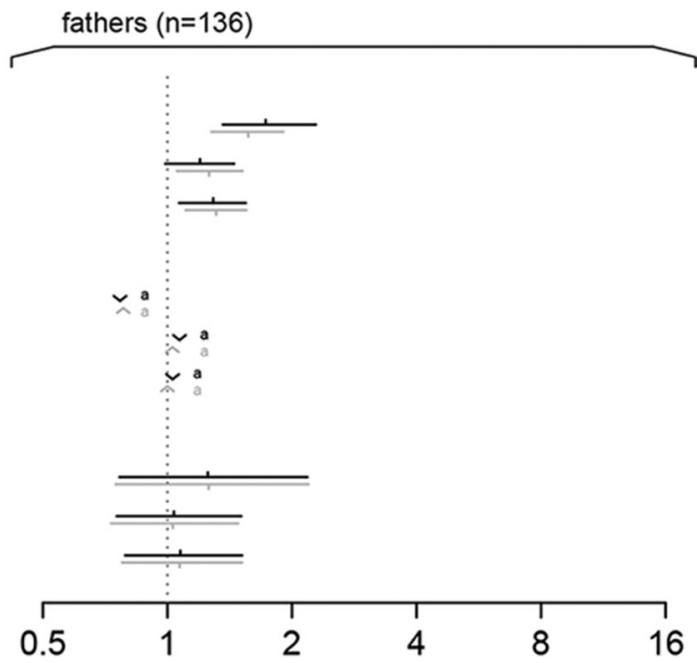

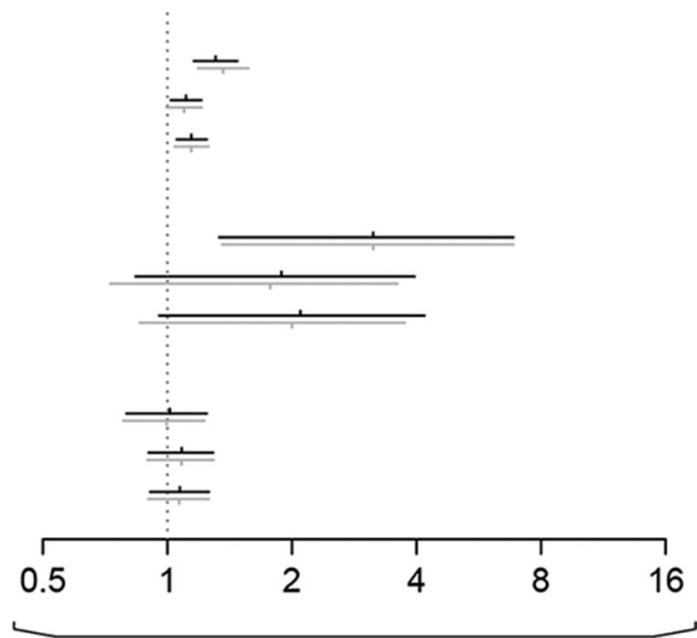

rate ratio, $95 \% \mathrm{Cl}$

$(\rightarrow)$ in favor of post-disaster increase

Figure 3 Rate ratios of parents' postdisaster versus predisaster healthcare consumption, in terms of (A) predicted frequency of healthcare service consumption (age-adjusted negative binomial hurdle regressions) and (B) observed proportions of individuals provided for (mean semiannual values). 95\% Cls of the ratios were generated through bootstrap replications. Corresponding numerical values are available in online supplementary table $4 .{ }^{\mathrm{a}}$ indicates that ratio of estimates could not be reliably bootstrapped.

\section{DISCUSSION}

The overall aim of this study was to make a detailed description of predisaster and postdisaster healthcare consumption in parents of the Utøya terrorist attack survivors. We found that primary healthcare was the larger provider of healthcare services both before and after the terrorist attack. The number of services provided to both mothers and fathers increased soon after the terrorist attack and peaked within the first 6 -month period. The increase in primary healthcare services both in the early and delayed aftermath was largely attributable to psychological health complaints, as recorded by their primary healthcare provider. In Norway, primary healthcare is the entry point to specialised healthcare, as well as to social benefits and public welfare services. Our figures suggest an important role for GPs in managing parents' postdisaster distress. GPs need to be aware that high numbers of parents may turn to primary healthcare with psychological health complaint in the wake of a terrorist attack, enabling appropriate preparations.

Increase in postdisaster primary healthcare consumption was most notable in female participants. Previous research has identified female survivors of trauma as more susceptible to developing PTSD than men. ${ }^{40} 41$ Thus, our data may in part reflect gender differences in postdisaster stress reactions. However, an alternative explanation 


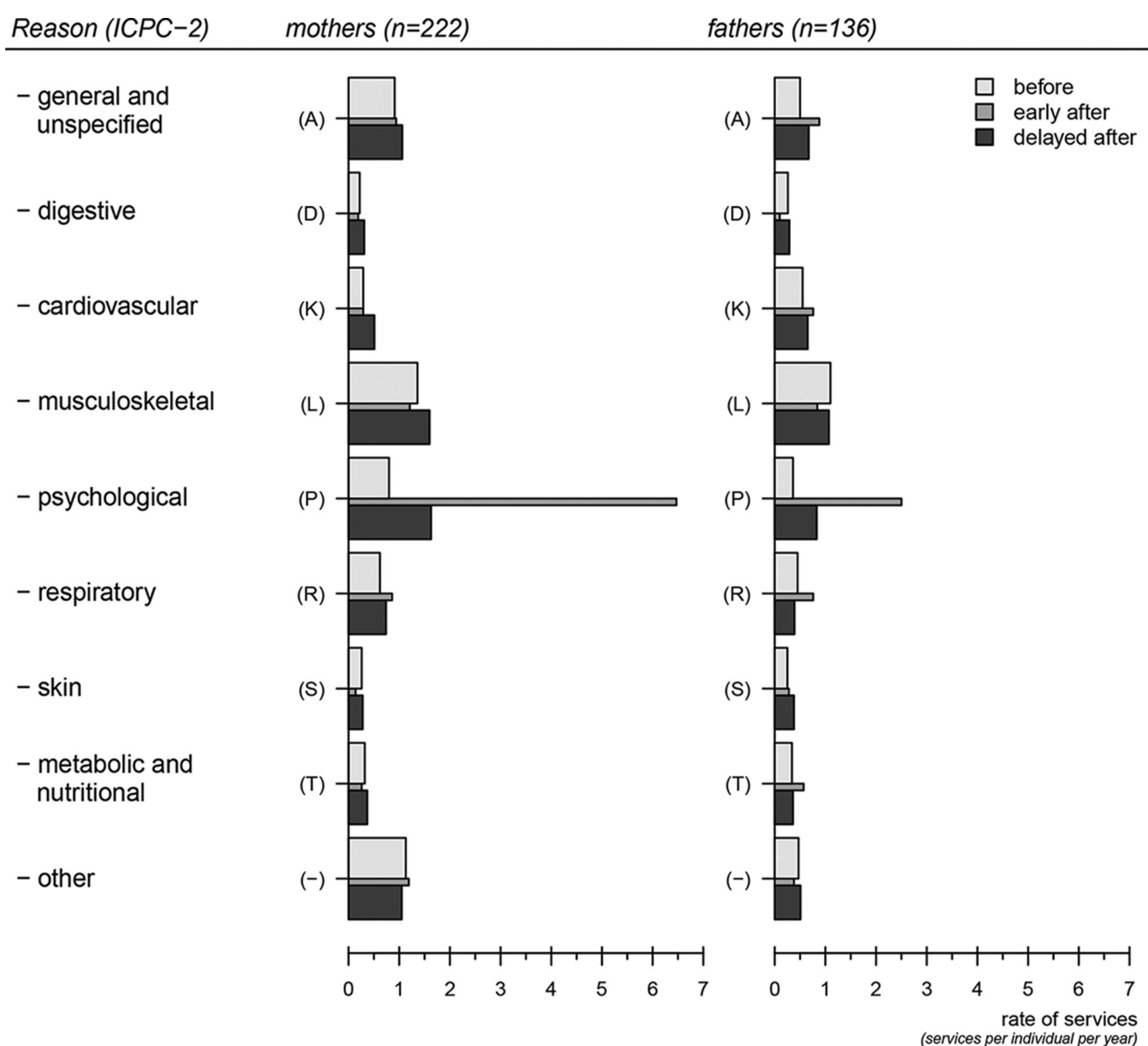

is that distressed fathers may have been more reluctant than mothers to seek help for mental health complaints, as has been suggested by previous research. ${ }^{42}{ }^{43}$ Potential barriers to accessing postdisaster healthcare in men and women should be further addressed in future research.

A significant increase in numbers of both mothers and fathers accessing specialised mental healthcare services was found in the current study. This finding is in line with our previous work, demonstrating significant associations between the parents' post-traumatic stress reactions and their self-reported specialised healthcare consumption in the early aftermath of the terrorist attack. ${ }^{28}$ Lack of capacity or capability of the primary healthcare services in providing for traumatised patients, including lack of appropriate experience or expertise, may have contributed to early referrals to the specialised healthcare services in some patients. However, in keeping with a registry-based study of the psychiatric diagnoses assigned by Swedish specialised mental healthcare providers to survivors of the 2004 Southeast Asian Tsunami, ${ }^{44}$ the increase in specialised mental healthcare consumption is likely largely to include the most severely traumatised parents-those in need of specialised mental healthcare interventions.
In the aftermath of disaster, an increase in healthcare consumption may result from both new patients entering the healthcare system and an increase in frequency of service consumption among those already in the services. ${ }^{45}$ In our study, most participants were found to use primary healthcare services both before and after the terrorist attack. Thus, the increased primary healthcare service consumption stemmed largely from an increase in frequency of healthcare consumption in individuals that were already known to the services. In contrast, the specialised mental healthcare services faced an influx of patients that were largely new to the services. Potential differences in patterns of parents' postdisaster healthcare consumption according to disaster characteristics, including disaster magnitude, duration and potential for damage, whether it being a natural or a man-made disaster, whether it being a shared or a non-shared trauma of parent and child, and postdisaster access to psychosocial services, are still largely to be investigated.

\section{Strengths and limitations}

The context of this study is a universal, public, accessible and well-developed healthcare system. The study 
employs an objective measure on healthcare consumption, recorded by the healthcare provider at the time of the healthcare service provision. The study allows for reliable comparison of predisaster and postdisaster data, with negligible levels of missing data. Nonetheless, observed healthcare consumption does not objectively reflect the healthcare needs. Consumption may represent a combination of the perception of needs of a patient deciding to seek medical advice and the clinical judgement of a provider, who, for example, may encourage renewed contacts, make referrals, among others. Although most applicable in similar clinical settings, we hold that our findings may reflect underlying postdisaster distress and thereby healthcare needs that may arise in parents anywhere in the world, in the face of terror. Whether similar patterns of healthcare needs arise in parents after other types of shared or non-shared traumatic exposures, such as when a child is struck by a natural disaster, traffic accident or serious illness, remains to be investigated.

The current study reports healthcare services provided by healthcare professionals only. Thus, parts of the postdisaster outreach programme were not included. ${ }^{28}$ In the aftermath of a terrorist attack, many countries are likely to adopt some kind of crisis response, as was reported following the major terrorist attacks in France ${ }^{46}$ and the UK. ${ }^{47}$ The organisation and contents of such programmes vary across different country settings. ${ }^{48}$ Following the Utøya terrorist attack, a majority of the mothers and fathers were contacted by proactive outreach services in their municipalities. ${ }^{28}$ Psychosocial support through postdisaster outreach may facilitate access to regular healthcare services and thus potentially increase overall healthcare consumption. On the other hand, it may also alleviate early health complaints and thus reduce consumption. The contents of the psychosocial services provided to parents are not known in detail. No adjustment for engagement with the outreach programme was made. Finally, although uncommon due to universal coverage of the national insurance scheme, some participants may have self-financed access to additional healthcare services or obtained services abroad.

\section{CONCLUSION}

Widespread healthcare needs have previously been reported among survivors of terrorist attacks. ${ }^{49}$ Our study emphasises the importance of thinking about survivors in a broader, more systemic way. Postdisaster increase in healthcare needs may not be limited to individuals rescued from the site of a terrorist attack, but may also include close family members, such as parents.

Correction notice This article has been corrected since it first published. The legend was missing from Figure 1 and has now been added in.

Acknowledgements The authors thank the participants of this study for their participation. The authors also thank the Norwegian Directorate of Health-

Norwegian Health Economics Administration and the Norwegian Patient Registry for making healthcare registry data available to us.
Contributors JMH, ST, LES and GD conceived of the study and developed the study design with TW-L. JMH, LES and GD gathered the data. JMH and TW-L conducted the statistical analyses. JMH wrote the first draft of the paper. All authors contributed to further drafts and approved the final submission, had full access to all of the data (including statistical reports and tables) in the study and can take responsibility for the integrity of the data and the accuracy of the data analysis. $\mathrm{JMH}$ is the guarantor of the manuscript being an honest, accurate and transparent account of the study being reported; that no important aspects of the study have been omitted; and that any discrepancies from the study as planned (and, if relevant, registered) have been explained.

Funding The research was funded by grants from the Norwegian Research Council and the Norwegian Directorate of Health.

Competing interests All authors have completed the International Committee of Medical Journal Editors uniform disclosure form at www.icmje.org/coi_disclosure. pdf and declare: the study was supported by the Norwegian Directorate of Health; JMH and LES have received research grants from the Norwegian Research Council; no other relationships or activities that could appear to have influenced the submitted work. All researchers worked independently from funders.

\section{Patient consent Obtained.}

Ethics approval Consents to participation and collection of registry-based data were obtained in writing from all participants. The study was approved by the Regional Committees for Medical and Health Research Ethics in Norway.

Provenance and peer review Not commissioned; externally peer reviewed.

Data sharing statement Data supporting the findings of this study are not publicly available. The patient-level, registry-based data may be accessed through the Norwegian Directorate of Health (https://helsedirektoratet.no/english). Restrictions apply. Technical appendix and statistical code are available from the corresponding author.

Open Access This is an Open Access article distributed in accordance with the Creative Commons Attribution Non Commercial (CC BY-NC 4.0) license, which permits others to distribute, remix, adapt, build upon this work non-commercially, and license their derivative works on different terms, provided the original work is properly cited and the use is non-commercial. See: http://creativecommons.org/ licenses/by-nc/4.0/

(c) Article author(s) (or their employer(s) unless otherwise stated in the text of the article) 2017. All rights reserved. No commercial use is permitted unless otherwise expressly granted.

\section{REFERENCES}

1. American Psychiatric Association. Diagnostic and statistical manual of mental disorders. 5th ed. Washington, DC: APA, 2013.

2. Scrimin S, Axia G, Capello F, et al. Posttraumatic reactions among injured children and their caregivers 3 months after the terrorist attack in Beslan. Psychiatry Res 2006;141:333-6.

3. Dyb G, Jensen TK, Nygaard E, et al. Post-traumatic stress reactions in survivors of the 2011 massacre on Utøya Island, Norway. Br J Psychiatry 2014;204:361-7.

4. Suomalainen L, Haravuori $\mathrm{H}$, Berg $\mathrm{N}$, et al. A controlled follow-up study of adolescents exposed to a school shooting--psychological consequences after four months. Eur Psychiatry 2011;26:490-7.

5. Barron J. Nation reels after Gunman massacres 20 children at school in connecticut. The New York times. 2012.

6. Paris attacks: What happened on the night. BBC 2015.

7. Orlando Shooting. The New York Times. 2016.

8. Schmidt M, Azoulay E. Having a loved one in the ICU: the forgotten family. Curr Opin Crit Care 2012;18:540-7.

9. Nelson LP, Gold Jl. Posttraumatic stress disorder in children and their parents following admission to the pediatric intensive care unit: a review. Pediatr Crit Care Med 2012;13:338-47.

10. Cabizuca M, Marques-Portella C, Mendlowicz MV, et al. Posttraumatic stress disorder in parents of children with chronic illnesses: a meta-analysis. Health Psychol 2009;28:379-88.

11. Vanderwerker LC, Laff RE, Kadan-Lottick NS, et al. Psychiatric disorders and mental health service use among caregivers of advanced cancer patients. J Clin Oncol 2005;23:6899-907.

12. Kassam-Adams N, Fleisher CL, Winston FK. Acute stress disorder and posttraumatic stress disorder in parents of injured children. $J$ Trauma Stress 2009;22:294-302.

13. Allenou C, Olliac B, Bourdet-Loubère $S$, et al. Symptoms of traumatic stress in mothers of children victims of a motor vehicle accident. Depress Anxiety 2010;27:652-7. 
14. Dyb G, Holen A, Steinberg AM, et al. Alleged sexual abuse at a day care center: impact on parents. Child Abuse Negl 2003;27:939-50.

15. Timmons-Mitchell J, Chandler-Holtz D, Semple WE. Post-traumatic stress symptoms in mothers following children's reports of sexual abuse: an exploratory study. Am J Orthopsychiatry 1996;66:463-7.

16. Dirkzwager AJ, Bramsen I, Adèr $\mathrm{H}$, et al. Secondary traumatization in partners and parents of Dutch peacekeeping soldiers. J Fam Psychol 2005;19:217-26.

17. Slaven-Lee PW, Padden D, Andrews CM, et al. Emotional distress and health risk behaviours of mothers of United States Marines. Int Nurs Rev 2011;58:164-70.

18. Schuster MA, Stein BD, Jaycox L, et al. A national survey of stress reactions after the September 11, 2001, terrorist attacks. N Engl J Med 2001;345:1507-12.

19. Rubin GJ, Brewin CR, Greenberg N, et al. Psychological and behavioural reactions to the bombings in London on 7 July 2005: cross sectional survey of a representative sample of Londoners. BMJ 2005;331:606.

20. Rubin GJ, Brewin CR, Greenberg N, et al. Enduring consequences of terrorism: 7-month follow-up survey of reactions to the bombings in London on 7 July 2005. Br J Psychiatry 2007;190:350-6.

21. Thoresen S, Aakvaag HF, Wentzel-Larsen T, et al. The day Norway cried:proximity and distress in Norwegian citizens following the 22nd July 2011 terrorist attacks in Oslo and on Utoya Island. Eur $J$ Psychotraumatol 2011;3.

22. Miguel-Tobal JJ, Cano-Vindel A, Gonzalez-Ordi H, et al. PTSD and depression after the Madrid March 11 train bombings. J Trauma Stress 2006;19:69-80.

23. Gabriel R, Ferrando L, Cortón ES, et al. Psychopathological consequences after a terrorist attack: an epidemiological study among victims, the general population, and police officers. Eur Psychiatry 2007;22:339-46.

24. Schnurr PP, Green BL, Kaltman S. Trauma exposure and physical health. New York: The Guilford Press, 2007.

25. Boscarino JA. Posttraumatic stress disorder and physical illness: results from clinical and epidemiologic studies. Ann NY Acad Sci 2004;1032:141-53

26. Pacella ML, Hruska B, Delahanty DL. The physical health consequences of PTSD and PTSD symptoms: a meta-analytic review. J Anxiety Disord 2013;27:33-46.

27. Dorn T, Yzermans JC, Spreeuwenberg PM, et al. Physical and menta health problems in parents of adolescents with burns--a controlled longitudinal study. J Psychosom Res 2007;63:381-9.

28. Haga JM, Stene LE, Wentzel-Larsen T, et al. Early postdisaster health outreach to modern families: a cross-sectional study. BMJ Open 2015;5:e009402.

29. Thoresen S, Jensen TK, Wentzel-Larsen T, et al. Parents of terror victims. A longitudinal study of parental mental health following the 2011 terrorist attack on Utøya Island. J Anxiety Disord 2016;38:47-54

30. Bugge I, Dyb G, Stensland S $\varnothing$, et al. Physical injury and posttraumatic stress reactions. A study of the survivors of the 2011 shooting massacre on Utøya Island, Norway. J Psychosom Res 2015;79:384-90.

31. Bisson JI, Tavakoly B, Witteveen AB, et al. TENTS guidelines: development of post-disaster psychosocial care guidelines through a Delphi process. Br J Psychiatry 2010;196:69-74.

32. Dyb G, Jensen T, Glad KA, et al. Early outreach to survivors of the shootings in Norway on the 22nd of July 2011. Eur $J$ Psychotraumatol 2014;5:5:23523.

33. Ringard À, Sagan A, Sperre Saunes I, et al. Norway: health system review. Health Syst Transit 2013;15:1-162.

34. Stene LE, Dyb G. Research participation after terrorism: an open cohort study of survivors and parents after the 2011 Utøya attack in Norway. BMC Res Notes 2016;9:57.

35. World Organization of Family Doctors (Wonca). ICPC-2-R. International Classification of Primary Care. Revised Second Edition. Oxford: Oxford University Press, 2005.

36. Britt $H$, Angelis M, Harris E. The reliability and validity of doctorrecorded morbidity data in active data collection systems. Scand J Prim Health Care 1998;16:50-5.

37. Hintze JL, Nelson RD. Violin plots: a box plot-density trace synergism. The American Statistician 1998;52:181-4.

38. Elhai JD, Calhoun PS, Ford JD. Statistical procedures for analyzing mental health services data. Psychiatry Res 2008;160:129-36.

39. Zeileis A, Kleiber C, Jackman S. Regression models for count data in R. J Stat Softw 2008;27:1-25.

40. Olff M, Langeland W, Draijer N, et al. Gender differences in posttraumatic stress disorder. Psychol Bull 2007;133:183-204.

41. Tolin DF, Foa EB. Sex differences in trauma and posttraumatic stress disorder: a quantitative review of 25 years of research. Psychol Bull 2006;132:959-92.

42. Addis ME, Mahalik JR. Men, masculinity, and the contexts of help seeking. Am Psychol 2003;58:5-14.

43. Oliver MI, Pearson N, Coe N, et al. Help-seeking behaviour in men and women with common mental health problems: cross-sectional study. Br J Psychiatry 2005;186:297-301.

44. Arnberg FK, Gudmundsdóttir R, Butwicka A, et al. Psychiatric disorders and suicide attempts in Swedish survivors of the 2004 southeast Asia tsunami: a 5 year matched cohort study. Lancet Psychiatry 2015;2:817-24.

45. Rosendal S, Mortensen EL, Andersen HS, et al. Use of health care services before and after a natural disaster among survivors with and without PTSD. Psychiatr Serv 2014;65:91-7.

46. Vandentorren S, Paty AC, Baffert E, et al. Syndromic surveillance during the Paris terrorist attacks. Lancet 2016;387:846-7.

47. Brewin CR, Scragg P, Robertson M, et al. Promoting mental health following the London bombings: a screen and treat approach. $J$ Trauma Stress 2008;21:3-8.

48. Dückers MLA, Witteveen AB, Bisson Jl, et al. The association between disaster vulnerability and post-disaster psychosocial service delivery across Europe. Adm Policy Ment Health 2017;44:470-9.

49. Brewin CR, Fuchkan N, Huntley Z, et al. Outreach and screening following the 2005 London bombings: usage and outcomes. Psychol Med 2010;40:2049-57. 